IP Periodica Polytechnica Civil Engineering

\author{
60(2), pp. 269 279 2016 \\ DOI: $10.3311 /$ PPci.8896 \\ Creative Commons Attribution (1) \\ RESEARCH ARTICLE
}

\section{Examination of the Physico-chemical Composition of Dispersive Soils}

\author{
Gábor Nagy, László Nagy, Katalin Kopecskó
}

Received 10-12-2015, revised 27-12-2015, accepted 05-01-2016

\begin{abstract}
When it comes to flood protection, the established method is to use an impermeable material in dikes, to prevent seepage. This material is usually some type of clayey soil which is considered as watertight and erosion-resistant. Despite that, in many occasions not only seepage, but the failure of the dam occurred due to surface erosion, because dispersive behavior is barely investigated, and their presence are not considered during the phase of design.

The term "dispersive clay" refer to a cohesive soil, which has an unfavorable property compared to other clays. Therefore the application of these kind of clays in flood protection structures, like dikes cannot be considered as a solution for the seepage problems. Dikes constructed from dispersive soils often fail to achieve the main idea of flood protection: keeping the downstream face relatively dry.

Earlier experiences stated that the dispersive behavior is related to the physico-chemical composition of the soil, therefore in this paper a few Hungarian soils, which are identified as dispersive are examined with geotechnical, agricultural and phase analytical methods.
\end{abstract}

\section{Keywords \\ Dispersive clay $\cdot$ pinhole test $\cdot$ sodic soil $\cdot$ phase analytics $\cdot$ geotechnical risk}

\section{Gábor Nagy}

Department of Engineering Geology and Geotechnics Faculty of Civil Engineering, Budapest University of Technology and Economics, H-1111 Budapest, Múegyetem rkp. 3, Hungary

e-mail: nagy.gabor@epito.bme.hu

\section{László Nagy}

Department of Engineering Geology and Geotechnics Faculty of Civil Engineering, Budapest University of Technology and Economics, H-1111 Budapest, Múegyetem rkp. 3, Hungary

e-mail: nagy.laszlo@epito.bme.hu

\section{Katalin Kopecskó}

Department of Engineering Geology and Geotechnics Faculty of Civil Engineering, Budapest University of Technology and Economics, H-1111 Budapest, Múegyetem rkp. 3, Hungary

e-mail:kopecsko.katalin@epito.bme.hu

\section{Introduction}

Dispersive clays can be found in many different places around the world, and they are connected to several dike failures in the past 60 years. Their presence in the Carpathian Basin is also known [12], in this paper results from Hungarian soil samples are presented.

The failures due to dispersive soils in the dikes are mostly occurred at relatively small hydraulic gradient, and the structural failure proceeds rapidly [13, 14]

The term 'dispersive clay' refers to special clay soils, where the physico-chemical composition of the soil can cause clay particles to deflocculate in the presence of relatively pure water [7]. These soils are so poorly bound, that this small amount of water flow can lead to structural breakdown, resulting dike breaches, failures. The effect caused several damages and failures of dikes and earth dams in the past years, therefore the presence itself recently is considered as a geotechnical risk in the process of design. The deflocculation process - which results from the structural breakdown due to the water flow - is the dispersion, where the soil grains and the water behave like a dispersive solution, and by that showing minimal resistance against external forces.

In 1980 a serious dike breach was observed along the river Sebes-Körös. The breach affected the full height of the dike with its crest height of 3-4 meters. The failure affected a 52 meters long section of the dike, causing several damages on the upstream face due to the flood [5].

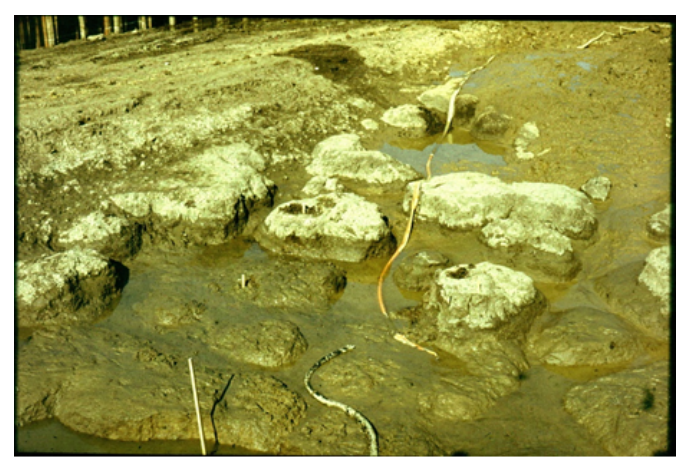

Fig. 1. Dispersive soil after the flood in 1980.

Since 1982 two Hungarian National Technical Directives con- 
tain specifications of the investigation of dispersive behavior of fill materials in dike and earth dam construction [15]:

- MI 10-268/1: Examination of the soils and building materials of flood protection embankments,

- MI 10-268/2: Equipment, measurement and classification of the examination of the soils and building materials of flood protection embankments.

This makes the investigation of dispersive behavior mandatory in case of flood protection structures, where soils are used as a fill material.

In the recent years extensive research have been carried out out to get a better understanding of the reasons related to the dispersive behavior [6, 21, 22]. Therefore the investigation of physical and chemical properties have been made.

The results showed that the dispersive behavior can be connected with the amount of dissolved salts in the soil extract. Since these are related to the origin of sodic soils, the following question arises, is there a correlation between the geotechnical "dispersive" and agricultural "sodic" terms?.

\section{Properties of dispersive soils}

Clays are susceptible of volume change depending on the amount of pore water, and the external temperature. During a warm period, drying cracks can develop on the surface of the dike, which under rainfall can be filled with water.

The mechanism of failure is the erosion. The rainfall can produce small tunnel-shaped cavities on the surface of the embankment, which opens the soil structure allowing water to flow through the soil. In this case a concentrated leak is created on the downstream face of the dike caused by the water flowing through the pores of the soil. The erosion starts at the end of the leak, and as it is progressing to the upstream face a tunnelshaped passage is formed. It is the result of the deflocculation, and not the seepage, like in other erosion problems [7].

The erosion patterns can easily be mixed up, therefore the identification of the form of the erosion is important, to connect it to the corresponding soil type. Table 1 contains the similar erosion types, and the related soils [16].

Table 1 shows that the dispersive behavior should only be considered with cohesive, fine grained soils. This can be explained by the structures of the cohesive soils.

\subsection{Theoretical background}

The cohesive soils are built up from platelets, with ions and water between the layers. In a non-sodic soil, mostly calcium is adsorbed on the surface of the clay. When the soil interacts with the water, the soil swells due to the water molecules between the platelets, but since the calcium has a strong charge, the binding forces between the platelets are not overcome, the soil structure stays intact.

In the case of the sodic soil, the ions adsorbed on the surface of the platelet in most cases identified as sodium, which is poorly bonded. If water is added to the system, the swelling of the soil begins, but in this case the binding between the platelets is overcome, significant swelling occurs. With further increasing of the amount of water between platelets, the soil disperses with water, the soil structure breaks down [2]. The two types of this swelling is demonstrated on Fig. 2

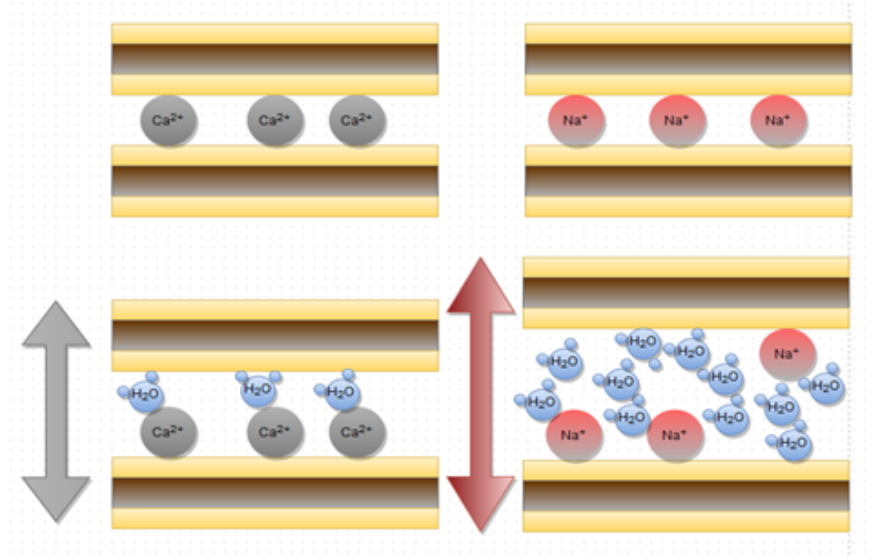

Fig. 2. Mechanism of soil swelling due to water (After DPIW [2]

As the dispersive behavior is connected to the physicochemical properties, the composition of these kind of clays are often examined. The theoretical background is the following: these soils are highly erodible due to their unfavorable structure. In slightly saline water, or water with moderate electrolyte concentration, cohesive soils usually swell, but rarely disperse [9]. Sherard in the 1970's recommended a method based on the amount of the exchangeable sodium in the soil compared to the total dissolved salts (TDS), resulting to a categorization of the dispersive behavior (Fig. 3 after Sherard [19]) as dispersive, intermediate and non-dispersive.

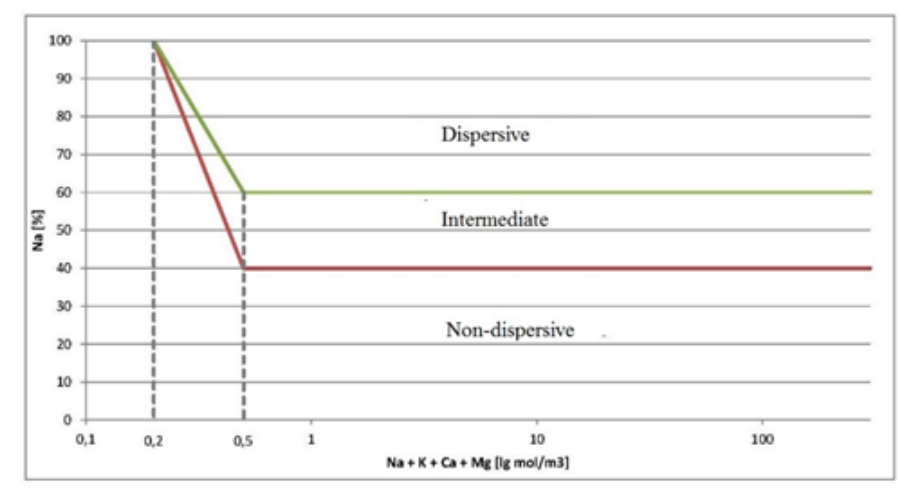

Fig. 3. Dispersive categories based on the amount of exchangeable sodium (After Sherard [19])

However, this classification method requires at least $60 \%$ of the exchangeable cations to be sodium, which is relatively high. Another research [22] have shown that dispersive behavior was observed with less sodium than Sherard's method suggests.

One explanation can be the presence of anions bonded to the cations, because the behavior of a material depends on the anions also, but Sherard's method takes only the amount of cations into consideration. 
Tab. 1. Erosion types in different soils [16

\begin{tabular}{cccc}
\hline Phenomenon & Effect & Type of soil & Phenomenon \\
\hline Dispersion & $\begin{array}{c}\text { Physico-chemical } \\
\text { composition }\end{array}$ & Fine grained soils & Dispersion \\
\hline Suffosion & Instable soil structure & Gap graded soils & Suffosion \\
\hline Piping & Pore water pressure rises & $\begin{array}{c}\text { Fine graded, } \\
\text { non-cohesive soils }\end{array}$ & Piping \\
\hline
\end{tabular}

Later it was also identified, that Sherard's method of categorization based on TDS is not accurate enough, in many cases soils with small amount of dissolved sodium also dispersed however the method identified them as non-dispersive or intermediate. Based on the Tasmanian Department of Primary Industries and Water (DPIW) [2] the tunnel erosion which is connected to dispersive behavior occurs with greater than $6.0 \%$ ESP, where ESP is the percentage of the amount of sodium ions divided by the amount of the TDS. The solution was the introduction of the pinhole test (the method itself is explained in Section 4.1.)

\subsection{Origin}

The Tasmanian Department of Primary Industries and Water collected some climatic factors for the dispersive soil formation. After the manual of the DPIW [2], the most important factors are:

- moderately steep $\left(>10^{\circ}\right)$ slopes,

- areas with less than $650 \mathrm{~mm}$ annual rainfall,

- areas, where seasonal, or highly variable rainfall is combined with high summer temperature,

- cracking of soils, due to desiccation.

Although these factors are stated to the Tasmanian sites, it is worth mentioning, that the last three of the four factors are valid in large part of the Hungarian Great Plain, and the moderately steep slope can be true to the edges of the Carpathian Basin, which allowed rivers to leave their settlements in the East and North-east area of Hungary, after they left the hills and their flow velocity decreased, allowing the alluvium to settle. Fig. 4 and 5 shows the circled areas in Hungary where the climatic factors are met. Large part of the Hungarian Great Plain is affected, and these are the areas where most dike breaches occurred which were identified as due to dispersive soil behavior.

The samples which were examined during the research were also taken from locations inside the circled area, from dikes along rivers Kőrös, Hortobágy-Berettyó and Tisza.

The pink spots on both maps are representing the saline soils. Fig. 4 and 5 suggests, that there is a correlation between the dispersive and saline soils, therefore the correlation of the two terms is examined.

\section{Properties of saline soils}

In order of a better understanding of the dispersive behavior, the properties of the saline soils are also important to consider.

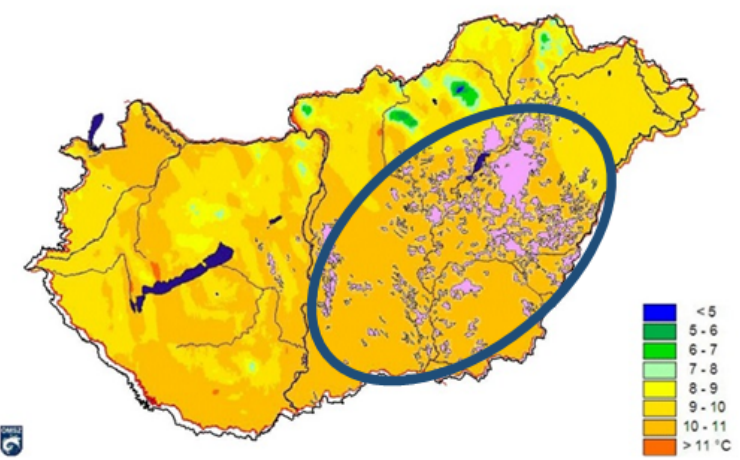

Fig. 4. Annual average temperature map of Hungary (source: www .met.hu)

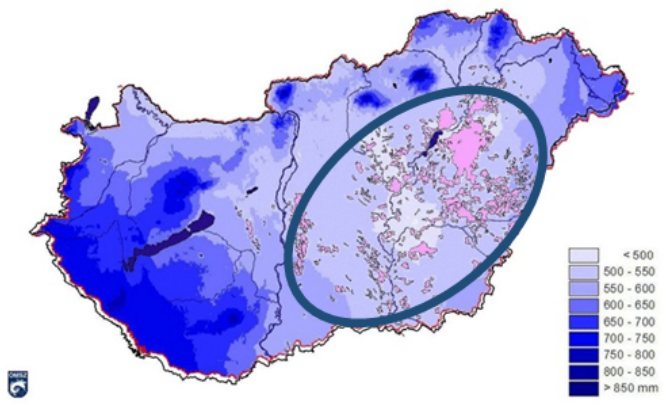

Fig. 5. Annual rainfall map of Hungary (source: www .met.hu)

As it is presented on Fig. 4 and 5 the areas where saline soils are located in Hungary are almost perfectly overlapping with the areas where soils which are susceptible for dispersive behavior can be found. Also, as the early method of identification (Sherard [18]) suggested the classification to be based on the amount of dissolved sodium and TDS values, the saline soils are also known for their dominant chemical composition.

Saline soil is an agricultural term, referring to a soil which went under the process of increasing the salt content known as salinization. Salinization can be caused by natural processes such as mineral weathering or by the gradual withdrawal of an ocean. It can also come about through artificial processes such as irrigation.

The saline content and the surface of sodic soils are leading to an assumption that there might be a relationship between the term sodic soil and dispersive soil. She et al. [20] suggest, that increase in sodicity or decrease of salinity of soils results in increase of the repulsion forces between clay particles.

The chief characteristic of sodic soils from the agricultural stand point is that they contain sufficient exchangeable sodium to adversely affect the growth of most crop plants. For the pur- 
pose of definition, sodic soils are those which have an exchangeable sodium percentage (ESP) of more than 15. The soils lack appreciable quantities of neutral soluble salts but contain measurable to appreciable quantities of salts capable of alkaline hydrolysis, e.g. sodium carbonate. The electrical conductivity (EC) of saturation soil extracts are, therefore, likely to be variable but are often less than $4 \mathrm{dS} / \mathrm{m}$ (at $25^{\circ} \mathrm{C}$ ). The $\mathrm{pH}$ value of saturated soil pastes is 8.2 or more and in extreme cases may be above 10.5 .

For sodic soils with $\mathrm{pH}$ higher than 8.0 there is a good estimation for the ESP value based on the $\mathrm{pH}$ of the saturated soil paste (Table 2).

Tab. 2. Approx. ESP values based on the $\mathrm{pH}$ of the saturated soil paste [4]

\begin{tabular}{cc}
\hline pH of saturated soil paste & Approximate ESP \\
\hline $8.0-8.2$ & $5-15$ \\
\hline $8.2-8.4$ & $15-30$ \\
\hline $8.4-8.6$ & $30-50$ \\
\hline $8.6-8.8$ & $50-70$ \\
\hline $8.8-$ & 70 \\
\hline
\end{tabular}

Based on Table 2 pH 8.2 can be referring to a soil which has an approximate ESP value of 15 , what is enough to be called dispersive hence DPIW suggests that ESP higher than 6.0 is enough to be susceptible of dispersion. This suggests that the dispersive categorization is a weaker criterion than the sodic at this standpoint.

\section{Laboratory testing methods}

In order to understand and identify the dispersive behavior, several approaches and testing methods can be used, according to the property of the soil which is the subject of the investigation. In this research testing methods of three disciplines was used with the same aim, to obtain information about the exact composition of these soils and the factors which are leading to the dispersive behavior.

Therefore beyond the geotechnical identification (pinhole test), the agricultural testing methods (electrical conductivity, $\mathrm{pH}$ and $\mathrm{pNa}$ measurement), and chemical analytical methods, like X-ray diffraction (XRD), and differential thermal analysis (DTA) have been carried out. The following sections are demonstrating shortly each of the used testing methods.

\subsection{Geotechnical identification of dispersive soils}

The simple field testing methods like the drop test or the crumb test [7] are capable of giving a rough estimation of the suspected dispersive behavior of the soils, based on their results samples can be collected for more accurate laboratory testing. These are based on the principle that in the presence of water the soil disperses, therefore in a small Petri dish the dispersion of the soil with some added water can be observed.

The most recognized laboratory test is the pinhole test. The method and the device were developed by Sherard et al. [18].
The device and the method are based on a hydraulic approach. For the test a compacted cylindrical specimen is needed. The method simulates the flow of water through a crack by punching a $1.0 \mathrm{~mm}$ diameter hole in the specimen with an iron pin, and distilled water can percolate through it. If the sample is dispersive clay, the flow breaks down grains from the soil structure, and the flowing water becomes a dispersive solution.

The equipment is capable of modelling different hydraulic conditions, therefore 4 different pressure heads can be applied: 50, 180, 380 and $1020 \mathrm{~mm}$. Dispersive clays erode at the smaller heads, consequently erosion-resistant soils can withstand $1020 \mathrm{~mm}$ water pressure without major particle movements. During the test, the flow velocity, and the eroded grains are observed. The device can be seen in Fig. 6

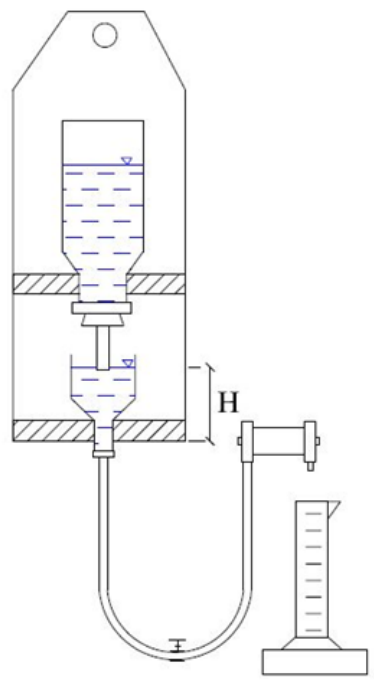

Fig. 6. Pinhole test device (Sherard [18])

" $\mathrm{H}$ " is the pressure head, which is applied on the sample. This potential will start the seepage, and increasing the applied value causing a higher level of hydraulic pressure to the soil structure, and a larger flow velocity. The output of the test is a classification based on the method after Sherard et al. [17]

Tab. 3. Dispersive categories

\begin{tabular}{ccc}
\hline Non-dispersive & Intermediate & Dispersive \\
\hline ND1, ND2 & ND3, ND4 & D2, D1 \\
\hline
\end{tabular}

Based on Sherard [18], the D1 and D2 dispersive categories are representing soils which are capable of suffering piping failure and severe erosion damage due to rainfall in earth dams and embankments, the ND1 and ND2 classifications are the nondispersive erosion resistant soils, which are applicable for embankments. The intermediate classifications, ND3 and ND4 indicate soils with potential of behaving like the dispersive soils, but the rate of erosion is lower compared to soils from D1 or D2 categories. This led to the following:

- D1, D2 categories cannot be used in flood protection structures. 
- ND4, ND3 categories are susceptible of dispersion, therefore their use in flood protection is not recommended, but after further investigation (and/or with soil treatment) they can be used in some cases.

- ND2, ND1 categories are the erosion-resistant soils which can be used as fill material to prevent seepage.

\subsection{Agricultural testing methods}

Based on Waskom et al. [23] the main causes of saline soils are measurable by electrical conductivity (EC), $\mathrm{pH}$, and high sodium content. Therefore the laboratory testing is based on the measurement of these three. All testing was performed on a soil suspension prepared by the following order:

- Pulverized soil samples are dried in $105^{\circ} \mathrm{C}$ in a heating oven.

- 30 grams of the soil are weighted out with grain size less than $2 \mathrm{~mm}$.

- The dry soil is mixed with $75 \mathrm{~cm}^{3}$ of boiled distilled water to create a 1:2.5 proportion suspension.

- The soil suspension is at rest for 24 hours.

After the 24 hours three testing method can be performed in the following order:

- Measurement of electrical conductivity.

- Measurement of $\mathrm{pH}$.

- Measurement of pNa.

Different order of measurements can result misleading results, because during the measurement of $\mathrm{pH}$ ions can get to the solution, which leads different value of the EC, therefore testing the electrical conductivity has to be the first to perform.

Before the measurement takes place the suspension has to be shaken to prevent any sedimentation which can stick to the measuring head, and giving inaccurate result.

Fig. 7. shows the equipment with the measuring unit. The measurement of the $\mathrm{pH}$ value is performed with the same equipment but different head.

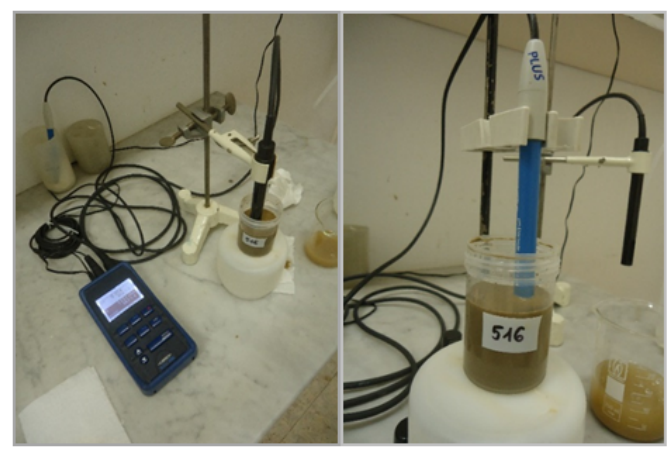

Fig. 7. EC measuring equipment and different head to measure the $\mathrm{pH}$

\subsection{Phase analytical methods}

In order to determine the exact composition of the soils, phase analytical methods were used. During the research X-ray powder diffraction (XRD) and simultaneous thermal analyses (TG/DTG/DTA) were carried out.

Both test requires powder-fine ground samples. Powder diffraction is a widespread method in the identification and characterization of crystalline solids. The ground soil samples contain randomly oriented particles. In a multi-phase mixture, e.g. a soil sample, more diffraction pattern of a poor crystalline phase (so-called fingerprint) superposed, allowing the determination of the phases in the mixture [8]. X-ray powder diffraction analyses were carried out using a Philips PW 3710 diffractometer. Parameter values of measurements were: generator tension $40 \mathrm{kV}$, generator current $30 \mathrm{~mA}$, tube anode $\mathrm{Cu}$ (long fine focus), wavelength (Alpha 1) $1.54060 \AA$, with monochromator. To the analysis and evaluation of samples the PC-APD (Version 3.5) software and the Total Access Diffraction Database PDF-2 (PLUS 42) database and software were used.

The X-ray diffraction is a nondestructive test, for that reason the thermal analyses were performed on the same samples. The DTA analysis, differential thermal analysis - as the name suggests it - where the thermal properties of two materials are compared. One is a thermally inactive, so called inert material (reference sample, usually kaolinite or corundum $\left[\mathrm{Al}_{2} \mathrm{O}_{3}\right]$ ). The apparatus is basically a furnace, where the two samples placed in sample holders. Both sample holders are connected with thermocouples, and the temperature is calculated from the voltage of the thermocouple in the sample holder. The inert sample is placed in one of these holders, the sample to be measured is in the other holder [8]. As the temperature is raised, the sample goes through either physical or chemical processes that produce or adsorb more heat from the sample. The temperature differences between the thermocouples are detected during the measurement.

The measurement range extends generally from room temperature up to $1000^{\circ} \mathrm{C}$. The inert material does not go through any changes within the measuring range. The change in mass is also observed during the measurement (thermogravimetric curve) and the first derivative is obtained from this thermogravimetric data (Derivative thermogravimetric curve). The results indicated by on curves:

- DTA curve: differential thermal analysis,

- TG curve: thermogravimetry,

- DTG curve: differential of the TG curve.

Fig. 8 shows a DTA test result. The three different colored areas are connected to weight losses due to different reasons. The first one (at lowest temperature) is related to the physically bound water, the next is by the clay minerals, and at the highest temperature, around $650^{\circ} \mathrm{C}$, the thermal decomposition of the carbonates has started. 


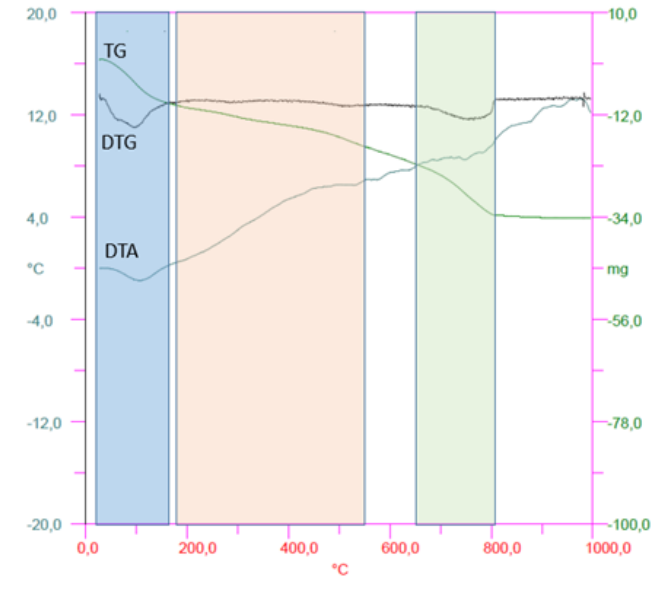

Fig. 8. DTG and TG curves of a dispersive soil sample

The thermoanalytical tests were made by using Derivatograph Q-1500D. There is a simultaneous procedure where the TG (Thermogravimetry) and DTA (Differential Thermal Analysis) thermoanalytical methods can be combined. As the result of thermogravimetry the first derivative of thermogravimetric curve (DTG) is also obtained. Reference material was alumina $\left(\mathrm{Al}_{2} \mathrm{O}_{3}\right)$, heating rate was $10^{\circ} \mathrm{C} / \mathrm{min}$ up to $\sim 1000^{\circ} \mathrm{C}$. Tests were carried under atmospheric pressure. The test results were evaluated by using Winder V 4.4 software.

\section{Geotechnical risks}

The main risk is originated from the fact that dispersive soils cannot be distinguished by visual classification, and the Atterberg limits or grain size distribution are also inadequate to determine whether the soil is dispersive or not. The finite element models or the calculation methods used are not able to handle the parameters which are describing the dispersive soils, therefore their evaluation has to be made separately.

As the phenomenon is known in Hungary since the late 70's, several research papers and technical reports were collected in order to examine the correlation of geotechnical classification and dispersive categories. In this paper results of 387 samples are presented. The distribution of soil types and the correlating dispersive categories are summarized in Table 4

Large part of this database is collected from research reports and expert opinions, where several test results were merged, therefore in many cases not a single percentage was given to the plasticity index, but a range from 2 to even 30 percentages. To examine the average plasticity indexes, only those results were used, which contained an exact value to the corresponding dispersive category. Table 5 contains the statistical analysis of 234 samples. It can be seen, that the number of the samples from the non-dispersive category decreased drastically. These reports focused on the dispersive and intermediate soils only, therefore when a sample was identified as non-dispersive, no further examination was made in many cases.

Based on Table 5 it can be stated, that all the dispersive and intermediate categories (D1, D2, ND4, ND3) are mostly high- or medium plasticity clays, but the dispersive classification (whether the soil is D1, D2, ND4 or ND3) cannot be distinguished by the plasticity index only. Also, in the case of nondispersive soils, the plasticity index decreases, the ND2, ND1 categories are low plasticity clays and silts. This confirms the theory, that if a dispersive soil is treated by e.g. lime, the plasticity index decreases, with more added lime, the plastic, cohesive soil becomes "granular" [11].

The plasticity index decreases by going from dispersive to non-dispersive, but the difference in the dispersive and intermediate categories is not significant. The standard deviation of the values confirms it, by giving large (8.2-11.1\%) values, while in the case of non-dispersive soils, the standard deviation is relatively small (1.8-2.6\%). Fig.9 9 represents the distribution of the plasticity index for each dispersive category.

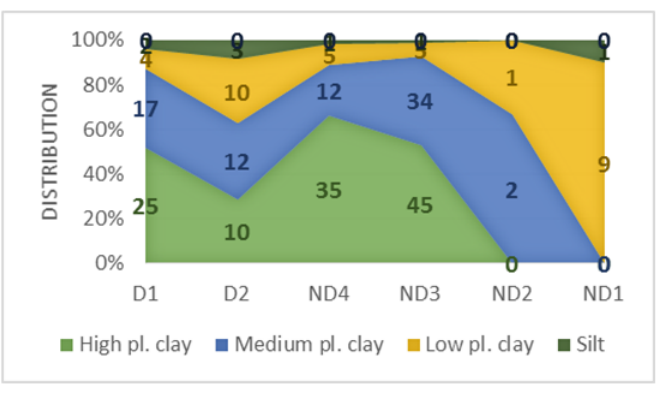

Fig. 9. Plasticity index of different dispersive categories

It show the tendency in the change of the soils plasticity index with the decreasing of the dispersive behavior. While in the dispersive and intermediate categories are mostly medium and high plasticity clays, the examined non-dispersive soils were classified as low plasticity clays, silts or even granular soils, which support the definition that the soil dispersion is a property of cohesive soils.

Evaluating the results from the recent years similarly as Table 4 the results are comparable. Fig. 10 presents the distribution of the measured data the similar way as Fig.9 During the testing of 49 soil samples, on which 98 pinhole test were performed, no soil with ND2 category was found. Each time the pinhole test has to be performed twice and the dispersive category has to be chosen considering the worst of the two results. ND2 category was given in a few cases, but the second measurement resulted as ND3, and the categorization led to intermediate in those cases.

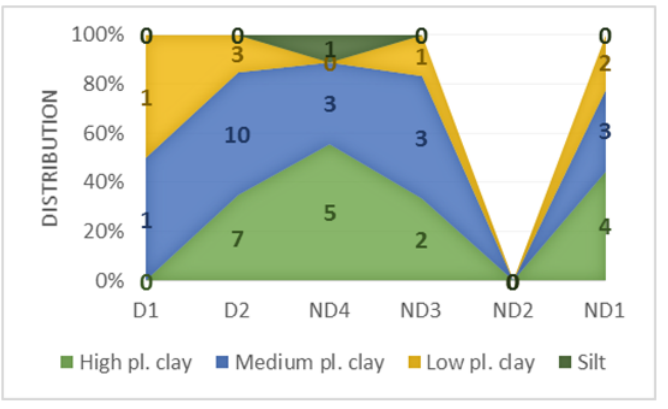

Fig. 10. Plasticity index of different dispersive categories 
Tab. 4. Plasticity index distribution of the soils

\begin{tabular}{|c|c|c|c|c|}
\hline Disp. category & $\begin{array}{c}\mathrm{I}_{p}>\mathbf{3 0 \%} \\
\text { (High pl. clay) }\end{array}$ & $\begin{array}{c}30 \%>I_{p}>20 \% \\
\text { (Medium pl. clay) }\end{array}$ & $\begin{array}{l}20 \%>I_{p}>15 \% \\
\text { (Low pl. clay) }\end{array}$ & $15 \%>I_{p}$ (Silt) \\
\hline D1 & 29 & 22 & 12 & 3 \\
\hline D2 & 13 & 12 & 16 & 3 \\
\hline ND4 & 35 & 15 & 3 & 1 \\
\hline ND3 & 45 & 34 & 5 & 0 \\
\hline ND2 & 51 & 39 & 9 & 1 \\
\hline ND1 & 11 & 13 & 10 & 2 \\
\hline
\end{tabular}

Tab. 5. Correlation of dispersive categories with the soils plasitcity index

\begin{tabular}{cccc}
\hline Dispersive category & No. of samples. & Average $\mathbf{I}_{P}[\%]$ & Standard deviation [\%] \\
\hline D1 & 48 & 33.4 & 10.8 \\
\hline D2 & 35 & 26.0 & 11.1 \\
\hline ND4 & 53 & 35.1 & 10.8 \\
\hline ND3 & 85 & 31.7 & 8.2 \\
\hline ND2 & 3 & 22.5 & 2.6 \\
\hline ND1 & 10 & 16.9 & 1.8
\end{tabular}

While the number of samples varies, some similarities can be found on Fig. 9 and 10 In both cases, the high and medium plasticity clays were the majority, and ND4 category had the most high plasticity clay. The range of the plasticity indexes are similar in both cases, the earlier tests showed a little larger values. The statistical values of the measured data are collected in Table 6

\subsection{Surface identification}

Fortunately, there are signs on the surface (e.g. crackings, sinkholes) from which the presence of dispersive soils can be assumed, and laboratory or field testing can be carried out. These surface crackings on the crest of the dike, which is usually a starting point of the erosion tunnel, and sinkholes on the edge of the crest or on the downstream face, are indicators of soils susceptible for dispersion [10]. Fig. 11] shows a typical surface drying crack on the crest of a dike, and also a small sinkhole (on the left side). These surface signs can help to identify the critical cross sections of flood protection structures, where soil dispersion can occur.

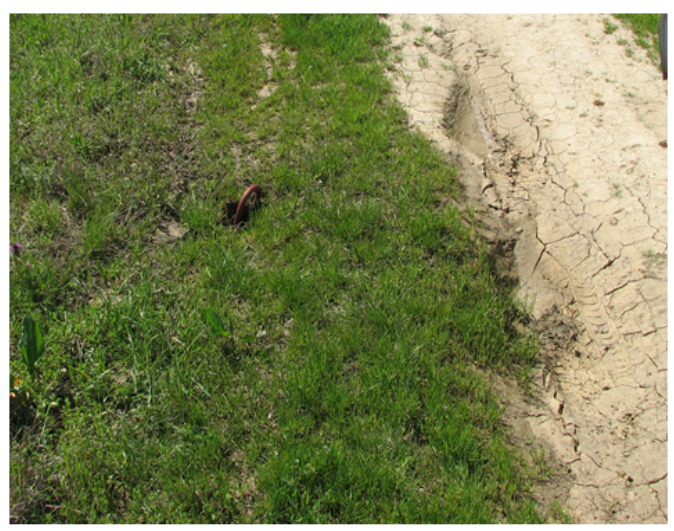

Fig. 11. Typical surface cracing and a small sinkhole

When these surface crackings or sinkholes are observed dur- ing an on-site investigation, samples can be taken from suspicious sections of the dikes, and laboratory test can be carried out in order to obtain information about the dispersive properties of the soils, and intervention can be made to prevent dike failure. One of the used methods is the soil treatment. Section 6 contains the results dispersive soil treated with slaked lime.

\section{Results of laboratory testing}

The testing of the soil samples were carried out in the following order:

- Geotechnical identification (plasticity index). Measured at the Budapest University of Technology and Economics, Department of Engineering Geology and Geotechnics, Soil Mechanics Laboratory.

- Pinhole testing to categorize the dispersive behavior as dispersive, intermediate, and non-dispersive. Measured at GeoHidro Kft.

- Measurement of $\mathrm{pH}, \mathrm{pNa}, \mathrm{EC}$ to get information about the physical composition. Measured at Institute for Soil Sciences and Agricultural Chemistry, Centre for Agricultural Research, Hungarian Academy of Sciences.

- XRD and DTA analyses to examine the mineral composition. Measured at the Budapest University of Technology and Economics, Department of Engineering Geology and Geotechnics, Phase Analytical Laboratory.

Earlier researches stated that the dispersive behavior is connected to the excess amount of sodium in the soil structure. Table 7 shows the results of $\mathrm{pNa}$ measurement, which is identical to the $\mathrm{pH}$, the negative logarithm of the sodium ion concentration in the soil suspension.

Based on that both pNa values of the dispersive and intermediate soils varied on a wide range, but there were no significant 
Tab. 6. Correlation of dispersive categories with the soils plasitcity index

\begin{tabular}{cccc}
\hline Dispersive category & No. of samples. & Average $\mathbf{I}_{P}$ [\%] & Standard deviation [\%] \\
\hline D1 & 2 & 23.4 & 5.4 \\
\hline D2 & 21 & 27.4 & 7.4 \\
\hline ND4 & 11 & 29.9 & 11.4 \\
\hline ND3 & 6 & 28.6 & 7.1 \\
\hline ND2 & N/A & N/A $/ A$ \\
\hline ND1 & 9 & 8.9 & 8.9 \\
\hline
\end{tabular}

differences between the values of the two groups. Dispersive soils $\mathrm{pNa}$ values were measured of 1.97-3.22, while in the case of intermediate soils pNa 1.82-3.53 was observed. The EC measurement showed the similar tendency, the wider range of values, but no significant differences between the two groups. This led to the assumption that although dispersive behavior cannot be independent from the presence of sodium ions, there has to be some other characteristic of the soil, which causes the unfavorable property.

In Table 7 the results of the first three testing is summarized. Based on the test results, soils categorized as dispersive (D1, D2) have $\mathrm{pH}$ 8.3-9.6, while the intermediate soils (ND4, ND3) a lower range, 7.8-9.0. The sodic soils are known for their high $\mathrm{pH}$ value [4], at least 8.2, all the D1, D2 categorized soils were found to be higher than that.

Dividing the intermediate group to ND4 and ND3, ND4 group, which is close to be categorized as D2 dispersive were found to have $\mathrm{pH} 8.1-9.0$, and only one sample had $\mathrm{pH}$ lower than 8.2, while in ND3 group the values ranged 7.8-8.8. It shows that the $\mathrm{pH}$ value decreases from going D1 dispersive category to ND4 intermediate. It can be assumed that the ND2 and ND1 categories, the non-dispersive soils have $\mathrm{pH}$ less than 7.8 , closer to the neutral $\mathrm{pH} 7.0$.

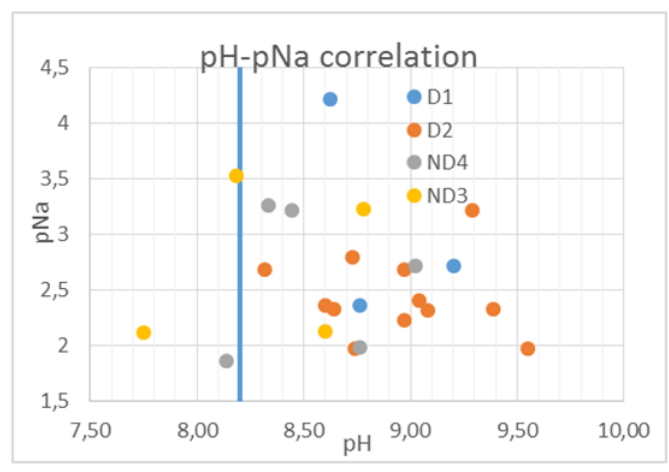

Fig. 12. Correlation of the measured $\mathrm{pH}$ and $\mathrm{pNa}$ values

Fig. 13 shows the correlation of the $\mathrm{pNa}$ and $\mathrm{EC}$ values of the examined soils in a log-log coordinate system. Based on Fig. 13 in the case of soils with the same value of $\mathrm{pNa}$, therefore the same sodium ion concentration, the dispersive soils are showing lower electric conductivity than the soils in the intermediate category, which is supporting the theory was mentioned in the case of Fig. 12, that the soil dispersion cannot only originated from the sodium ions in the soil structure.

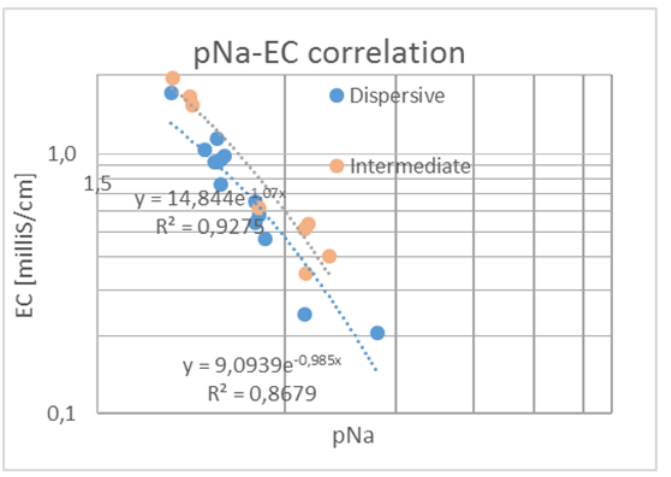

Fig. 13. Correlation of $\mathrm{pNa}$ and $\mathrm{EC}$ values

\subsection{Effect of soil treatment}

As the first section mentioned the basic idea is that the dispersive behavior of the soil can be related to the clay minerals, the physico-chemical properties. It was examined, whether the change of the chemical properties of the soils, can decrease the dispersive behavior. For that, laboratory tests were carried out. With two groups of soil samples taken from the Hungarian Great Plane, we added different amount of slaked lime. Earlier experiences and literature data showed that several material can be used to reduce the dispersive behavior, Table 8 presents a few of them.

First we needed to know if the soil we are using is dispersive or not. So the first step was to determine the category of dispersion based on Sherard [18].

Both sample groups were found to be in D2 category dispersive. We added 2.5, 4.0, 6.0 and 8.0 mass percent slaked lime to the soils in the first group, and the specimens were compacted with the Proctor device. After 48 hours rest, pinhole tests were carried out, and the results showed that even with $2.5 \%$ slaked lime the soil was classified as ND1, the less dispersive category.

This lead to the reevaluation of the amount of added lime. Therefore in the second phase of the research, 1.0, 1.5, 2.0, 2.5 mass percent slaked lime was used [11].

In this paper the changes of the physico-chemical composition of this samples due to the soil treatment are presented. The addition of lime to a soil increases the $\mathrm{pH}$ value, which could be predicted, and it was measured.

The lime $\left[\mathrm{Ca}(\mathrm{OH})_{2}\right]$ is alkaline, therefore the effect of the lime addition should increase the $\mathrm{pH}$ value. In the two groups the maximum added amount of lime was $4.0 \%$ which resulted in a high (11.0) $\mathrm{pH}$ value, but even a smaller amount, which was 
Tab. 7. Measured soil physical values

\begin{tabular}{|c|c|c|c|c|}
\hline Sample & Disp. category & $\mathrm{pH}[-]$ & pNa [-] & EC [milliS/cm] \\
\hline Cibakháza 4, 45+770 & D1 & 9.2 & 2.72 & 0.581 \\
\hline Hortobágy-Berettyó 54+740/1.3 m & D1 & 8.8 & 2.36 & 0.760 \\
\hline Tiszabura 4 & D2 & 9.3 & 3.22 & 0.242 \\
\hline Tiszabura 5 & D2 & 8.3 & 2.68 & 0.65 \\
\hline Berettyó 1 & D2 & 9.0 & 2.68 & 0.543 \\
\hline Berettyó $13+800$ & D2 & 9.4 & 2.33 & 0.925 \\
\hline Berettyó 13+000 & D2 & 8.7 & 2.79 & 0.472 \\
\hline Cihakháza 45+548 $0.4 \mathrm{~m}$ & D2 & 8.6 & 2.33 & 1.138 \\
\hline Karcag I. $0 \%$ & D2 & 9.1 & 2.31 & 0.928 \\
\hline Karcag II. $0 \%$ & D2 & 8.6 & 2.36 & 0.952 \\
\hline Hortobágy-Berettyó 54+550/0.4 m & D2 & 9.0 & 2.40 & 0.981 \\
\hline Hortobágy-Berettyó 54+610/2.8 m & D2 & 9.6 & 1.97 & 1.707 \\
\hline Hortobágy-Berettyó 54+630/0.7 m & D2 & 9.0 & 2.23 & 1.040 \\
\hline Tiszabura 2 & ND4 & 8.4 & 3.22 & 0.512 \\
\hline Tiszabura 3 & ND4 & 8.3 & 3.26 & 0.535 \\
\hline Zagyvarékas 2 & ND4 & 9.0 & 2.72 & 0.616 \\
\hline Cibakháza 45+548 0,8 m & ND4 & 8.8 & 1.98 & 1.956 \\
\hline Hortobágy-Berettyó 54+550/2.0m & ND4 & 8.1 & 1.86 & 0.003 \\
\hline Cibakháza 1 2.7-3.0 m & ND3 & 8.2 & 3.53 & 0.404 \\
\hline Tiszabura 1 & ND3 & 8.8 & 3.23 & 0.346 \\
\hline Cihakháza 45+548 $0.5 \mathrm{~m}$ & ND3 & 8.6 & 2.13 & 1.530 \\
\hline Hortobágy-Berettyó 54+730/1.8 m & ND3 & 7.8 & 2.11 & 1.660 \\
\hline
\end{tabular}

Tab. 8. Results of the treated soil samples

\begin{tabular}{|c|c|c|c|}
\hline Source & Material & Measurement & $\mathrm{m} / \mathrm{m} \%$ \\
\hline Ouhadi, Goodarzi [17] & Alum [Al2(SO4)3*18H2O] & Double hydrometer, XRD & $1.5-3.0$ \\
\hline Turkoz et. al 21 & $\mathrm{MgCl} 2$ & Pinhole, XRD & $7.0-9.0$ \\
\hline Goodarzi, Salimi 6 & Furnace slag (BOFS, GBFS) & Double hydrometer & $5.0-15.0$ \\
\hline Bell, Maud 1. & Slaked lime $[\mathrm{Ca}(\mathrm{OH}) 2]$ & $\mathrm{N} / \mathrm{A}$ & $3.0-4.0$ \\
\hline Elgers 3 & Gypsum $\left(\left[\mathrm{CaSO}_{4}{ }^{*} 2 \mathrm{H} 2 \mathrm{O}\right]\right.$ & $\mathrm{N} / \mathrm{A}$ & 2.0 \\
\hline
\end{tabular}

enough to reduce the dispersive behavior $(2.0 \%)$ led to $\mathrm{pH} 9.0$.

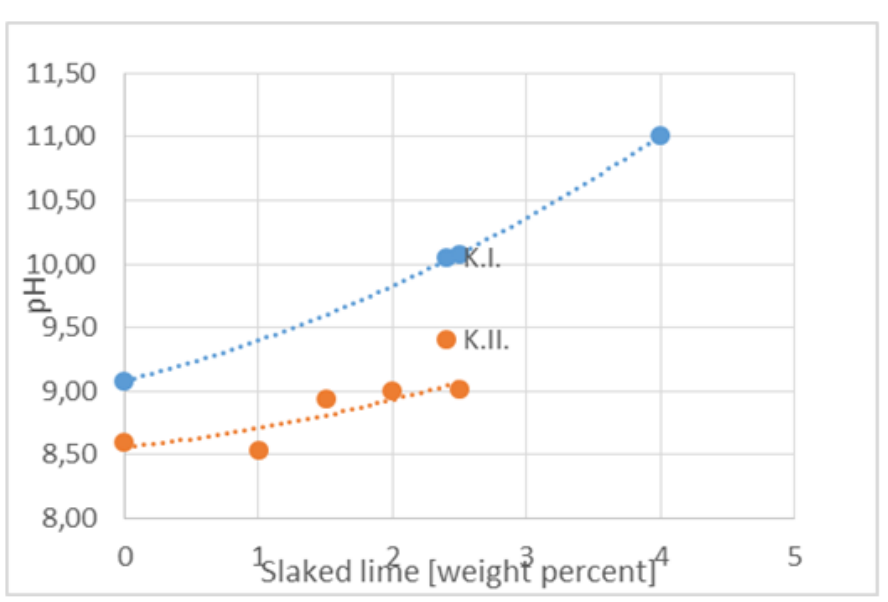

Fig. 14. Effect of the added slaked lime on the $\mathrm{pH}$ of the sample

This amount of lime was not enough to change the $\mathrm{pNa}$ value significantly. Same can be said about the EC, where the ions added to the soil suspension were not enough, to have great effect on the physical composition and on the electric conductivity, the maximum amount of added slaked lime was 4.0 mass percent. Table 9 shows the test results.

Tab. 9. Results of the treated soil samples

\begin{tabular}{ccccc}
\hline Sample & Disp. category & pH [-] & pNa [-] & EC [milliS/cm] \\
\hline K.I.0\% & D2 & 9.1 & 2.31 & 0.93 \\
\hline K.I.2.5\% & ND1 & 10.1 & 2.31 & 1.01 \\
\hline K.I.4.0\% & ND1 & 11.0 & 2.33 & 1.24 \\
\hline K.II.0\% & D2 & 8.6 & 2.36 & 0.95 \\
\hline K.II.1.0\% & ND4 & 8.5 & 2.24 & 1.20 \\
\hline K.II.1.5\% & ND3 & 8.9 & 2.45 & 0.85 \\
\hline K.II.2.0\% & ND1 & 9.0 & 2.26 & 0.97 \\
\hline K.II.2.5\% & ND1 & 9.0 & 2.25 & 0.98 \\
\hline
\end{tabular}

\subsection{Phase analytical methods}

The results from the agricultural measurements showed that some other material, mineral than the sodium ions in the soil structure has to be that is leading to the soil dispersion. XRD and DTA analyses were performed on 9 soil samples, four of them earlier categorized as dispersive (D1, D2) and five intermediate (ND4, ND3). Fig. 15 shows the X-ray diffractograms of the dispersive soils examined. None of them shows that large amount 
of clay minerals are present in the composition, which would suggest that the soil dispersion is only a result of the sodium, but as Fig. 15 shows, the composition of the materials is very similar, the peaks of the detected X-rays are located at the same degrees. For the sake of comparability, Fig. 16 shows an X-ray diffractogram of a bentonite sample, which is mostly built up from montmorillonite.

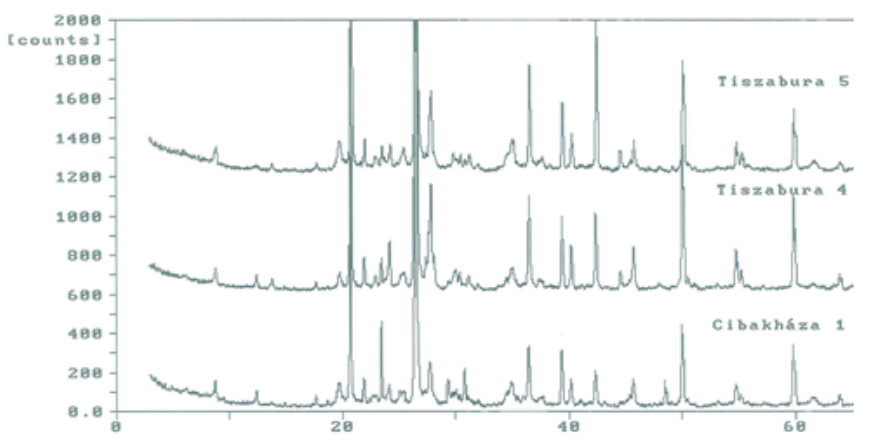

Fig. 15. X-ray diffractograms of D2 category soils

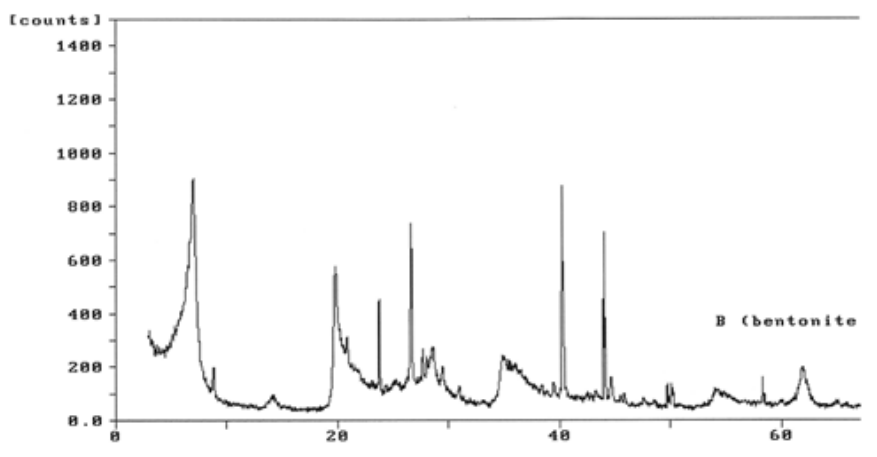

Fig. 16. X-ray diffractogram of a betonite sample

While the XRD is a qualitative test, the thermoanalysis could serve also with quantitative results. The heating of the sample and the weight losses on different heat scales are giving mass composition. The samples, and some minerals found during the tests are collected in Table 10 .

The aim was to get information about the mineralogical composition of the soils capable of tunnel erosion. Table 10 shows the small amount of total clay minerals in both the dispersive and intermediate categories. The sum of the detected clay minerals is 17-23 mass percent in most cases, i.e. the clay mineral content less than 25 mass percent is clay mineral in the soils examined. The XRD showed some other minerals which were dominant in the samples like quartz, feldspars (e.g. albite), micas (e.g. muscovite), and other silicates were found. Beside these minerals small amount of carbonate-type minerals (dolomite and calcite) were also found.

\section{Conclusions}

In geotechnical engineering, clays are considered as watertight and erosion-resistant materials, therefore they are used in dikes and earth dams as a fill material to prevent seepage, and leakage problems on the downstream face.
In some cases these cohesive soils behave in the presence of water like there were little bonding between the clay platelets, and the flow of the water is enough force to break down the soil structure and begin to erode the dike. These unusual soils are referred as dispersive soils. The biggest disadvantage of the dispersive soils is the likelihood of erosion due to rainfall or surface runoff.

This nature of the dispersive (clay) soils is leading to the necessity to monitor and evaluate dikes in order to prevent the failures due to the unfavorable properties of the soil.

Hungarian test reports and recent researches showed that while the dispersive behavior is the property of cohesive soil, it cannot be correlated to the plasticity index. Statistical analyses from 387 samples were collected, and 49 soil samples were tested by Sherard's pinhole test, and the plasticity index of the samples was determined. The following can be stated:

- The D1, D2 categories are mostly high and medium plasticity clays, with plasticity index of $23.4-34.4 \%$.

- The intermediate category (ND4, ND3) which is also susceptible for tunnel erosion was also found to be mostly high and medium plasticity clays, with slightly higher values, plasticity index of $28.6-35.1 \%$.

Earlier experiences and studies showed, that source of the behavior can be found in the examination of the physical and chemical properties. Therefore several laboratory testing method were developed (ESP, SAR, EC, pH measurements, etc.) to get a better point of view on the properties of dispersive soils. Our results showed that in many cases the dissolved salts and ionic composition of the minerals are leading to the unfavorable properties. These factors however, are also connected to an agricultural term sodic soils.

Laboratory tests were carried out in order to get information about both the dispersive and sodic properties of the soil samples. Two groups of samples were used, one with 22 soil samples taken from dikes, the other group with 8 samples known as dispersive soils, treated by slaked lime. All of the samples were tested by Sherard's pinhole test, to obtain their dispersive categories, and then chemical tests, $\mathrm{pH}, \mathrm{pNa}$ and EC measurements were carried out to compare the dispersive and sodic soil properties. Results of the measurements showed the following:

- Most of the dispersive soils were found to have $\mathrm{pH}$ value higher than 8.2, which is the lower limit of soil salinity.

- Most of the dispersive soils were found to have $\mathrm{pNa}$ value higher than 2.3, which is the upper limit of soil salinity.

- Examining the correlation of the electrical conductivity and the $\mathrm{pNa}$, with the same sodium ion concentration the dispersive soils have smaller EC values as the intermediate soils, therefore their unfavorable property cannot only due to the sodium ions in the soil structure. 
Tab. 10. Mineral comopsition of the samples

\begin{tabular}{|c|c|c|c|c|c|c|c|}
\hline Sample & Disp.cat. & $\begin{array}{l}\text { Chlorite } \\
\text { [mass \%] }\end{array}$ & $\begin{array}{c}\text { Illite } \\
\text { [mass \%] }\end{array}$ & $\begin{array}{l}\text { Montmorillonite } \\
\text { [mass \%] }\end{array}$ & $\begin{array}{l}\text { Total clay } \\
\text { minerals } \\
\text { [mass \%] }\end{array}$ & $\begin{array}{l}\text { Dolomite } \\
\text { [mass \%] }\end{array}$ & $\begin{array}{c}\text { Calcite } \\
\text { [mass \%] }\end{array}$ \\
\hline Cibakháza 4, 45+770 & D1 & $2-3$ & $7-3$ & 14-15 & $23-21$ & 6 & 0 \\
\hline Cibakháza 1, 0,9-1,1 m & D2 & $0-1$ & $6-3$ & $16-17$ & $19-21$ & 4 & 0 \\
\hline Tiszabura 4 & D2 & 0 & 1 & 5 & 6 & 1 & 0 \\
\hline Tiszabura 5 & D2 & 0 & $3-6$ & $19-18$ & $23-21$ & $0-1$ & 0 \\
\hline Zagyvarékas 2 & ND4 & $0-2$ & $12-6$ & $8-9$ & $20-17$ & 13 & 14 \\
\hline Tiszabura 2 & ND4 & $\mathrm{N} / \mathrm{A}$ & $\mathrm{N} / \mathrm{A}$ & $\mathrm{N} / \mathrm{A}$ & $42-36$ & 7 & 8 \\
\hline Tiszabura 3 & ND4 & $0-1$ & $5-2$ & $7-8$ & $13-11$ & 1 & 0 \\
\hline Cibakháza 1, 2,7-3,0 m & ND3 & $0-1$ & $7-4$ & $15-16$ & $22-21$ & 2 & 2 \\
\hline Tiszabura 1 & ND3 & $0-2$ & $12-5$ & $12-13$ & $24-23$ & 12 & 13 \\
\hline
\end{tabular}

Earlier it was found that the $2.0 \%$ of added slaked lime was enough to treat the dispersive behavior. Measurements showed that the side effect of the treatment is the increasing of the $\mathrm{pH}$, while this small amount of added calcium to the soil has no significant effect on the sodium concentration of the EC value. It is worth mentioning that from the agricultural point of view, the treatment with gypsum would be preferred, namely because gypsum does not increase the $\mathrm{pH}$ value as the hydroxide ions do.

Results showed that soils, which were described as dispersive (D1, D2) have $\mathrm{pH}$ value high enough (8.3-9.6) to characterize those as sodic soils $(\mathrm{pH}>8.2)$. The measurement of the electronic conductivity showed that the dispersive, and even the intermediate category of soils have less EC value (0.242$1.707 \mathrm{milliS} / \mathrm{cm}$ ), as the upper limit of the sodic soil categorization $(\mathrm{EC}<4.0 \mathrm{milliS} / \mathrm{cm})$. Therefore based on our experiences the dispersive and sodic terms for a soil can be associated, the test results showed that for these soils the criteria to be categorized as sodic soil are stronger conditions as it is in the case of the dispersive soils.

\section{References}

1 Bell FG, Maud RR, Dispersive soils: a review from a South African perspective, Quarterly Journal of Engineering Geology and Hydrogeology, 27(3), (1994), 195-210, DOI 10.1144/GSL.QJEGH.1994.027.P3.02

2 Dispersive soils and their management, Department of Primary Industries and Water, Tasmania, 2009.

3 Elgers HFWK, Dispersive soils, The Civil Engineer in South Africa, 27, (1985), 347-353.

4 Soils Bulletin \#39 Salt Effected Soils and their Management, Food and Agriculture Organization of the United Nations, 1988.

5 Felkai BO, Nagy L, Gátszakadás a vas-kapu helyén, Hidrológiai Közlöny, 94, (2012), 60-62. (in Hungarian).

6 Goodarzi AR, Salimi M, Stabilization treatment of a dispersive clayey soil using granulated blast furnace slag and basic oxygen furnace slag, Applied Clay Science, 108, (2015), 61-69, DOI 10.1016/j.clay.2015.02.024

7 Bulletin \#77 Dispersive soil sin embankment dams, International Commission on Large Dams, 1990.

8 Kopecskó K, Derivatográfia és Rtg-diffrakció mérnöki feladatok megoldásában, 10th International Conference on Civil Engineering and Architecture, In: Proceedings of the 10th International Conference on Civil Engineering and Architecture, 2006, pp. 134-141. (in Hungarian).
9 Mitchell JK, Fundamentals of Soil Behavior, Wiley Publications, 1974, ISBN 978-0-471-46302-3.

10 Nagy G, Diszperziv talajok azonosítása árvízvédelmi gátak felszínén megfigyelt károsodások alapján, 18th International Conference on Civil Engineering and Architecture, In: Proceedings of the 18th International Conference on Civil Engineering and Architecture, 2014, pp. 219-223. (in Hungarian).

11 Nagy G, Nagy L, Identification and Treatment of Erodible Clays in Dikes, 5th International Symposium on Geotechnical Safety and Risk, In: Geotechnical Safety and Risk V, 2015, pp. 530-534. (in Hungarian).

12 Nagy L, Dike breaches in the Carpathian Basin, Periodica Polytechnica Civil Engineering, 50, (2006), 115-124.

13 Nagy L, Estimating Dike Breach Length From Historical Data, Periodica Polytechnica Civil Enigneering, 50, (2006), 125-139.

14 Nagy L, Hydraulic failure probability of a dike cross section, Periodica Polytechnica Civil Engineering, 52, (2008), 83-89, DOI 10.3311/pp.ci.2008-2.04

15 Nagy L, Árvízvédekezés a településeken, Környezetvédelmi és Vízügyi Minisztérium, 2010, ISBN 978-963-06-7458-4. (in Hungarian).

16 Nagy L, Buzgárok az árvízvédelemben, Országos Vízügyi Főigazgatóság, 2014, ISBN 978-963-12-0319-6. (in Hungarian).

17 Ouhadi VR, Goodarzi AR, Assessment of the stability of a dispersive soil treated by alum, Engineering Geology, 85(1-2), (2006), 91-101, DOI 10.1016/j.enggeo.2005.09.042

18 Sherard JL, Decker RS, Ryker NL, Piping in earth dams of dispersive clays, In: Proceedings of the ASCE Specialty Conference on the Performance of Earth Structures, American Society of Civil Engineers, 1972, pp. 589-626.

19 Sherard JL, Dunnigan LP, Decker RS, Pinhole Test for Identifying Dispersive Soils, Geotechnical Engineering Division, 102, (1976), 69-85.

20 She D, Fei Y, Liu Z, Liu D, Shao G, Soil erosion characteristics of ditch banks during reclamation of a saline/sodic soil in a coastal region of China: Field investigation and rainfall simulation, CATENA, 121, (2014), 176-185, DOI $10.1016 /$ j.catena.2014.05.010

21 Turkoz M, Savas H, Acaz A, Tosun H, The effect of magnesium chloride solution on the engineering properties of clay soil with expansive and dispersive characteristics, Applied Clay Science, 101, (2014), 1-9, DOI 10.1016/j.clay.2014.08.007

22 Zorluer I, Icaga Y, Yurtcu S, Tosun H, Application of a fuzzy rulebased method for the determination of clay dispersibility, Geoderma, 160(2), (2010), 189-196, DOI 10.1016/j.geoderma.2010.09.017

23 Waskom RM, Bauder T, Davis JG, Andales AA, Diagnosing Saline and Sodic Soil Problems, Colorado State University, 2014. 